\title{
The use of metal piece additives to enhance heat transfer rate through an unconsolidated adsorbent bed
}

\author{
Hasan Demir ${ }^{a}$, Moghtada Mobedi ${ }^{b, *}$, Semra Ülkü ${ }^{a}$ \\ ${ }^{a}$ Department of Chemical Engineering, Izmir Institute of Technology, 35430 Urla, Izmir, Turkey \\ ${ }^{\mathrm{b}}$ Department of Mechanical Engineering, Izmir Institute of Technology, 35430 Urla, Izmir, Turkey
}

\section{A R T I C L E I N F O}

\section{Article history:}

Received 25 August 2008

Received in revised form

9 December 2009

Accepted 28 December 2009

Available online 13 January 2010

\section{Keywords:}

Adsorption system

Water

Silica gel

Improvement

Adsorber

Additive

Particle

Metal

Thermal conductivity

Bed

\section{A B S T R A C T}

The effects of metal piece additives on effective thermal conductivity and diffusivity of an unconsolidated adsorbent bed in which adsorbent is silica gel were investigated. The metal piece additives were copper, brass, aluminum and stainless steel with two different sizes as $1.0-2.8 \mathrm{~mm}$ and $2.8-4.75 \mathrm{~mm}$. The effective thermal conductivity and diffusivity of the mixed bed were predicted by comparison of the experimental results with the solution of dimensionless heat conduction equation for the bed. The performed experiments showed that the addition $15 \mathrm{wt} \%$ of aluminum pieces with sizes between 1.0 and $2.8 \mathrm{~mm}$ enhances the effective thermal diffusivity and conductivity of a pure silica gel bed by $157 \%$ and $242 \%$, respectively.

(c) 2010 Elsevier Ltd and IIR. All rights reserved.

\section{Additifs sous forme de particules métalliques utilisés afin d'augmenter le transfert de chaleur à travers un lit absorbant non consolidé}

\footnotetext{
* Corresponding author. Tel.: +90 23275067 09; fax: +90 2327506701.

E-mail address: moghtadamobedi@iyte.edu.tr (M. Mobedi).

0140-7007/\$ - see front matter @ 2010 Elsevier Ltd and IIR. All rights reserved.

doi:10.1016/j.ijrefrig.2009.12.032
} 


\begin{tabular}{ll}
\multicolumn{2}{l}{ Nomenclature } \\
$\alpha$ & thermal diffusivity, $\mathrm{m}^{2} \mathrm{~s}^{-1}$ \\
$\mathrm{Bi}$ & Biot number \\
$\mathrm{C}_{p}$ & specific heat, $\mathrm{Jg}^{-1} \mathrm{~K}^{-1}$ \\
$\mathrm{~K}$ & thermal conductivity, $\mathrm{W} \mathrm{m}^{-1} \mathrm{~K}^{-1}$ \\
$h_{\mathrm{w}}$ & wall heat transfer coefficient, $\mathrm{W} \mathrm{m} \mathrm{m}^{-2} \mathrm{~K}^{-1}$ \\
$\rho$ & density, $\mathrm{kg} \mathrm{m}^{-3}$ \\
$\mathrm{~T}$ & temperature, $\mathrm{K}$ \\
$\mathrm{t}$ & time (s) \\
$x$ & mass fraction, $\mathrm{kg}_{\mathrm{m}} \mathrm{kg}_{\mathrm{s}}^{-1}$ \\
$\tau$ & dimensionless time, $\alpha \mathrm{t} / \mathrm{R}^{2}$
\end{tabular}

$r^{*}$

$R \quad$ radius of glass cylinder

$\theta \quad$ dimensionless temperature, $\left(T-T_{\infty}\right) /\left(T_{i}-T_{\infty}\right)$

Subscripts

i initial

$\infty \quad$ bath temperature

m metal pieces

$\mathrm{s} \quad$ silica gel

w water

eff effective

\section{Introduction}

The number of studies on adsorption heat pump has increased in recent years since these systems can utilize directly solar and geothermal energies and waste heat of an industrial process. Despite many advantages of adsorption heat pump, it still has some drawbacks such as low specific cooling power (SCP) and coefficient of performance (COP). The main drawback of solid adsorbents used in the adsorption heat pumps is their poor thermal conductivity which is an important obstacle in the commercialization of adsorption heat pumps (Demir et al., 2008; Wang et al., 2005). Furthermore, the voids between the granules lead a discontinuity in the adsorbent bed and considerably reduce the effective thermal conductivity of adsorbent bed. In order to achieve a high SCP, the effective thermal conductivity of the adsorbent bed and adsorbents should be improved to have a high rate of heat transfer through the adsorbent bed.

In the literature, there are studies which have been performed to improve heat transfer through the granular adsorbent beds. Ülkü and Mobedi (1989) used fins to increase heat transfer area between adsorbent pellets and casing of bed. Gui et al. (2002) designed a shell tube adsorber and placed activated carbon among the tubes, used for adsorbent heating and cooling. The rib pieces on the tubes (i.e. fins) increased the rate of heat transfer from the tubes to the activated carbon. Critoph et al. (2000) developed a prototype of a fast cycle adsorption refrigerator composed of the laminate of monolithic carbon discs and aluminum. Saha et al. (2006) employed activated carbon fiber packed tightly inside copper fins for improving of heat transfer rate. Moreover, literature survey shows that the consolidated adsorbents may be an appropriate solution for increasing the effective thermal conductivity of adsorbent beds; however this solution should not cause the increase of mass transfer resistance of the adsorbent particle. Studies on consolidated adsorbent bed continue and a review on this technique was performed by Wang et al. (2005).

Although the application of fins is a proper method for improving heat transfer rate through an adsorbent bed, the method does not reduce discontinuity and thermal resistance between the adsorbent granules and also between the granules with the bed casing. The mixing of metal pieces with adsorbent granules seems an appropriate method to enhance the thermal conductivity and diffusivity of a granular adsorbent bed. Number of studies on the use of metal pieces in the adsorbent bed for enhancing heat transfer is limited. Eltom and Sayigh (1994) researched the effect of copper and graphite powder (without any treatment) additives on the thermal conductivities of charcoal. They found that these metal additives improve the thermal conductivity of charcoal from 2 to $25 \%$. Pino et al. (1996) performed an experimental study on the zeolite based composite materials. They tested several binders and additives with high thermal conductivity. Among different tested composite materials, it was observed that zeolite with aluminum hydroxide binder has the highest thermal conductivity.

The goal of the present study is to enhance the effective thermal conductivity and diffusivity of an adsorbent bed without increasing mass transfer resistance. The enhancement of effective thermal conductivity and diffusivity of a silica gel bed is examined by addition of various metal pieces to the adsorbent bed. The silica gel granules are mixed with four different metal pieces as aluminum, copper, brass and stainless steel (AISI-304). The experiments were performed for two sizes of metal pieces as $1.0-2.8 \mathrm{~mm}$ and $2.8-$ $4.75 \mathrm{~mm}$. The thermal conductivities of the pure and mixed adsorbent beds were determined by comparison of the experimental results with the solution of dimensionless form of conduction heat transfer equation for the adsorbent bed.

\section{Material and methods}

\subsection{Materials}

The silica gel was supplied from Merck Co. The equivalent diameter of silica gel granules varies between 3 and $5 \mathrm{~mm}$. BET surface area is $700 \mathrm{~m}^{2} \mathrm{~g}^{-1}$ and the average pore size of the silica gel is $2.0-2.5 \mathrm{~nm}$. The maximum water vapor adsorption capacity of silica gel is reported as $25 \%$ by manufacturer (Merck Co.).The stainless steel (St-St), copper (Cu), aluminum (Al) and brass (40\% Zinc, 60\% Copper) pieces were supplied from a local raw material firm and shown in Fig. 1. A special attention was paid during the selection of metal piece additives and the shapes of selected metal pieces do not have considerable effects on the mass transfer resistance through the bed. All metal pieces were washed with alcohol and were 

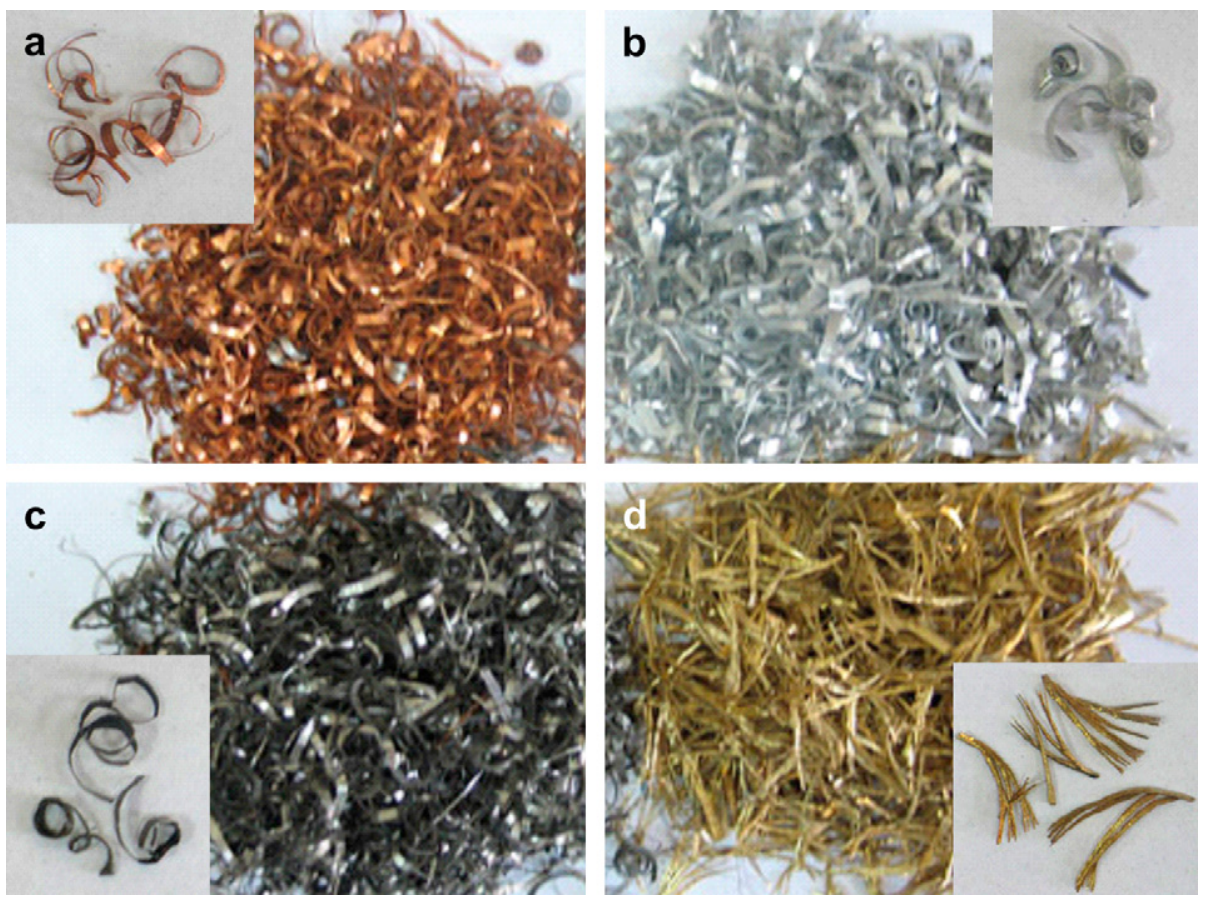

Fig. 1 - Photographs of used metal pieces: (a) copper; (b) aluminum; (c) stainless steel; and (d) brass.

sieved for separation into two fractions as $1.0-2.8 \mathrm{~mm}$ and 2.8-4.75 $\mathrm{mm}$. The Al, Cu and St-St metal pieces have almost spiral shape. The values $2.8 \mathrm{~mm}$ and $4.75 \mathrm{~mm}$ represent the equivalent radius of maximum frontal area on the sieve occupied by spiral metal pieces. The thickness and width of the metal strips are around $0.1 \mathrm{~mm}$ and $2 \mathrm{~mm}$, respectively. The shape of brass piece is different than the shapes of $\mathrm{Al}, \mathrm{Cu}$ and St-St metal pieces and it is like tiny hand fan as shown in Fig. 1(d). The length of the brass pieces is between 10 and $13 \mathrm{~mm}$. The thermal properties of the used metals confirmed by manufacturer are illustrated in Table 1.

\subsection{Experimental setup and procedure}

The schematic view of the test apparatus is shown in Fig. 2. The apparatus consists of a thin glass cylinder with length of $130 \mathrm{~mm}$ and the outer diameter $45 \mathrm{~mm}$, constant temperature water bath and thermocouples. The center temperature of the cylinder was measured by a grounded thermocouple having $120 \mathrm{~mm}$ length placed vertically in the cylinder center. Hence, the measured value is not a point wise temperature and it is the average temperature of cylinder center.
The silica gel granules were placed and saturated in ammonium chloride desiccator with $75 \%$ relative humidity for 5 days. Then, they were put into the thin glass cylinder quickly and the top of cylinder was covered perfectly to prevent the transfer of water vapor and gases to/from the cylinder during the experiment. The cylinder was fully and homogeneously filled with materials which are pure silica gel granules, pure metal pieces (copper, stainless steel, aluminum and brass) or silica gel-metal pieces mixture at different weight percentages as $5 \%, 10 \%$ and $15 \%$. A special attention was paid during the mixing of metal pieces with the silica gel to have a homogenous mixture. The filled glass cylinder was heated up to $40^{\circ} \mathrm{C}$ by using an electrical heater. After attaining the steady state, the apparatus was suddenly immersed into the constant temperature bath with water temperature as $5{ }^{\circ} \mathrm{C}$. The data acquired from thermocouples was processed by a data logger and saved in a computer. The thermocouples were calibrated by Fluke 714 temperature calibrator which has accuracy of $0.025 \%$. For the silica gel-metal mixture results, three experiments were performed. The standard deviations of the calculated thermal conductivity values of different experiments were found around $0.005 \mathrm{~W} \mathrm{~m}^{-1} \mathrm{~K}^{-1}$.

Table 1 - Thermal properties of the four used metals (Incropera and DeWitt, 1996).

\begin{tabular}{lccccc} 
Material & $\begin{array}{c}\text { Thermal Conductivity } \\
\left(\mathrm{W} \mathrm{m}^{-1} \mathrm{~K}^{-1}\right)\end{array}$ & $\begin{array}{c}\text { Density } \\
\left(\mathrm{kg} \mathrm{m}^{-3}\right)\end{array}$ & $\begin{array}{c}\text { Specific Heat } \\
\left(\mathrm{J} \mathrm{kg}^{-1} \mathrm{~K}^{-1}\right)\end{array}$ & $\begin{array}{c}\text { Thermal Capacitance } \\
\left(\mathrm{J} \mathrm{m}^{-3} \mathrm{~K}^{-1}\right)\end{array}$ & $\begin{array}{c}\text { Thermal Diffusivity } \\
\left(\mathrm{m}^{2} \mathrm{~s}^{-1}\right)\end{array}$ \\
\hline Copper & 401 & 8933 & 385 & $3.4 \times 10^{6}$ & $1.17 \times 10^{-4}$ \\
St-St (AISI-304) & 14.9 & 7900 & 477 & $3.8 \times 10^{6}$ & $3.95 \times 10^{-6}$ \\
Aluminum & 237 & 2702 & 903 & $2.4 \times 10^{6}$ & $9.71 \times 10^{-5}$ \\
Brass (40\%Zn 60\% Cu) & 150 & 8500 & 380 & $3.2 \times 10^{6}$ & $4.60 \times 10^{-5}$ \\
\hline
\end{tabular}




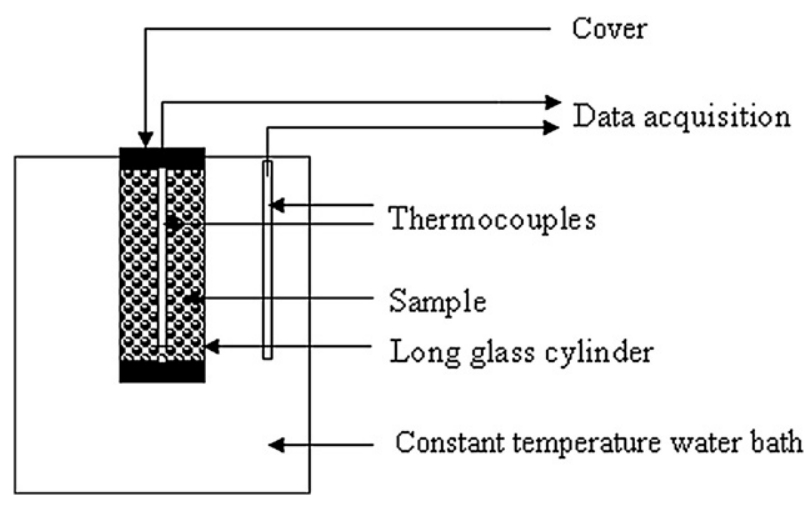

Fig. 2 - Schematic view of test apparatus.

\subsection{Determination of bed thermal diffusivity and conductivity}

For evaluation of the effective thermal diffusivity of the adsorbent bed, the solution of dimensionless form of transient heat conduction equation for the filled cylinder was obtained. The heat transfer resistance through the bed is described by an effective thermal conductivity, $K_{\text {eff, }}$ in radial direction. Due to low porosity and low values of Rayleigh number, the effect of natural convection heat transfer in the cavity is neglected. Moreover, the performed calculations showed that conduction thermal resistance of the glass cylinder and convective thermal resistance between glass cylinder and water of the bath are negligible and hence temperature of inner side of glass can be accepted equal to the water temperature in bath (i.e. $T_{\text {wall }}=T_{\infty}$ ). It should be mentioned that water in the constant temperature water bath is not in stationary state and water is circulated strongly and continuously around glass cylinder to provide constant and homogenous temperature in the water bath. This causes the increase of heat transfer coefficient between glass and circulated water. The another resistance that should be considered is the resistance between the glass wall and adsorbent granules and it is described by wall heat transfer coefficient;

$-K_{\text {eff }} \frac{\partial T}{\partial r}=h_{\mathrm{w}}\left(T-T_{\text {wall }}\right)$

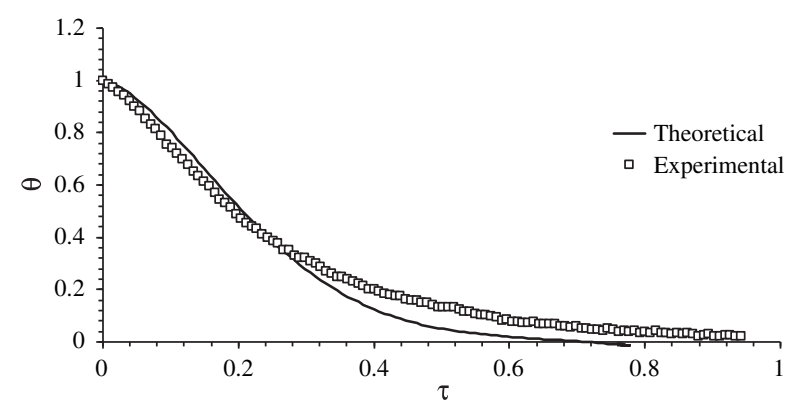

Fig. 3 - A representative plot related to the change of theoretical and experimental dimensionless center temperature with dimensionless time for $5 \% \mathrm{Cu}$-Silica gel mixture.
The value of wall heat transfer coefficient is assumed as $h_{\mathrm{w}}=50 \mathrm{~W} \mathrm{~m}^{-2} \mathrm{~K}^{-1}$ in this study (Freni et al., 2002; Aristov, 2009). The conduction heat transfer is function of time and radius since the lower and upper part of the glass cavity is insulated perfectly. The dimensionless form of one dimensional transient heat conduction equation for the cylinder is:

$\frac{\partial \theta}{\partial \tau}=\frac{1}{r^{*}} \frac{\partial}{\partial r^{*}}\left(r^{*} \frac{\partial \theta}{\partial r^{*}}\right)$

where $\theta$ is the dimensionless temperature and it is defined as $\theta=\left(\mathrm{T}-\mathrm{T}_{\infty}\right) /\left(\mathrm{T}_{\mathrm{i}}-\mathrm{T}_{\infty}\right) . \mathrm{T}_{\mathrm{i}}$ indicates initial temperature of the adsorbent bed. The independent parameters $\tau$ and $r^{*}$ represent the dimensionless time $\left(\tau=\alpha \mathrm{t} / \mathrm{R}^{2}\right)$ and radius. The boundary conditions for the problem can be written as:

at $r^{*}=0, \quad \partial \theta / \partial r^{*}=0$

at $r^{*}=1, \quad \partial \theta / \partial r^{*}=-B i \theta$

for $\tau=0, \quad \theta=1$

where $B i$ number is defined as $B i=h_{w} R / K_{\text {eff }}$. After obtaining the solution for heat conduction equation (Equation (1)), the variation of temperature of centerline $\left(r^{*}=0\right)$ with dimensionless time was drawn. The results of the experiment (i.e. centerline temperature versus time) were transformed to the dimensionless form and compared with the obtained theoretical solution. A trial and error approach was used to determine the effective thermal diffusivity of adsorbent bed. The value of thermal diffusivity of adsorbent bed was changed until to reach a sufficiently small deviation between the experimental results and theoretical values obtained by solution of Eq. (1). The multiplication of calculated thermal diffusivity with the effective thermal capacitance yields the effective thermal conductivity. The effective thermal capacitance of the mixture was calculated based on the weight percentage as:

$\left(\rho C_{p}\right)_{\text {eff }}=x\left(\rho C_{p}\right)_{\mathrm{m}}+(1-x)\left(\rho C_{p}\right)_{\mathrm{s}}$

It is clear that the obtained thermal conductivity and diffusivity shows the adsorbent bed effective thermal conductivity and diffusivity. After obtaining an effective thermal conductivity based on the procedure mentioned above, it is used to determine new value for $\mathrm{Bi}$ number since $B i=h_{\mathrm{w}} \mathrm{R} / \mathrm{K}_{\mathrm{eff}}$. The Equation (2) was solved again and the procedure is continued until the change of $K_{\text {eff }}$ with $\mathrm{Bi}$ number becomes negligible.

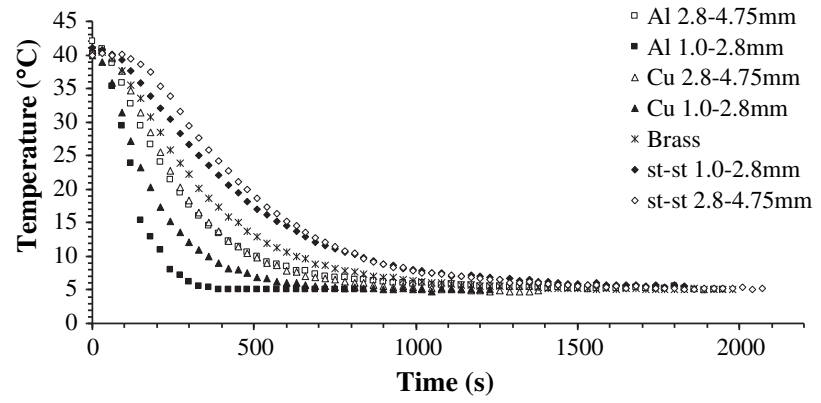

Fig. 4 - Variations of center temperature of bed contains metal piece with time. 


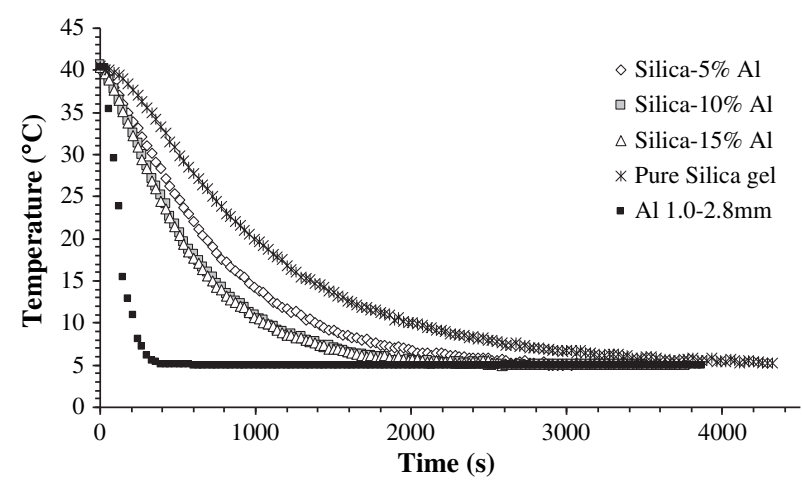

Fig. 5 - Variations of center temperature of Silica gel-Al adsorbent bed with $0 \%, 10 \%, 15 \%$ and $100 \%$ aluminum weight.

Fig. 3 shows a representative diagram in which both the variations of the measured temperature and the calculated dimensionless temperature with dimensionless time are presented for $5 \% \mathrm{Cu}$-Silica gel mixture. As is seen, a good agreement is observed between the experimental and theoretical values signifying the accuracy of the employed method.

\section{Results and discussions}

Fig. 4 shows the variations of center temperature with time for the four metal pieces of two different sizes as $1.0-2.8 \mathrm{~mm}$ and $2.8-4.75 \mathrm{~mm}$. For all metal pieces, the initial temperature is $40^{\circ} \mathrm{C}$ and it declines with time and then reaches $5^{\circ} \mathrm{C}$ which is temperature of the bath. The decreasing rate of temperature changes with the materials and their sizes. As is seen from Table 1, in which the thermal properties of four used materials (non-porous shape) are presented, the stainless steel has the minimum thermal diffusivity as $3.95 \times 10^{-6} \mathrm{~m}^{2} \mathrm{~s}^{-1}$. The thermal diffusivity of brass, aluminum and copper are $4.6 \times 10^{-5}, \quad 9.71 \times 10^{-5}$ and $1.17 \times 10^{-4} \mathrm{~m}^{2} \mathrm{~s}^{-1}$, respectively which are higher than stainless steel. Hence, the lowest heat transfer rate through the bed is expected for the beds contain stainless steel and then it should be followed by brass. The highest heat transfer rates are expected in the bed containing the aluminum and copper pieces. Fig. 4 almost validates the

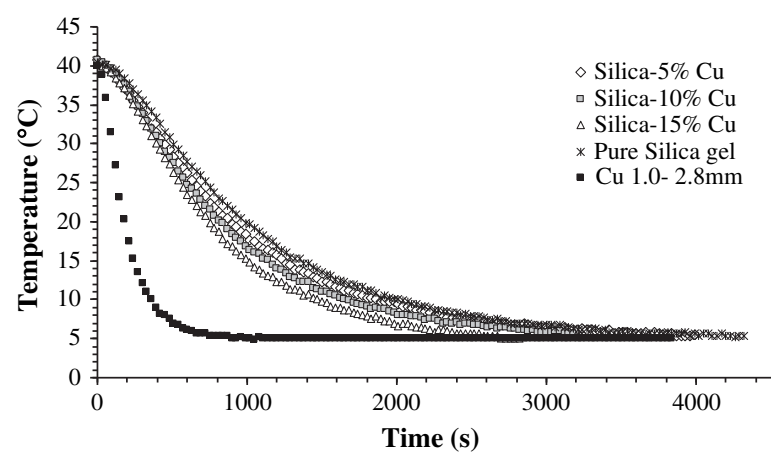

Fig. 6 - Variations of center temperature of Silica gel-Cu adsorbent bed with $0 \%, 10 \%, 15 \%$ and $100 \%$ copper weight.

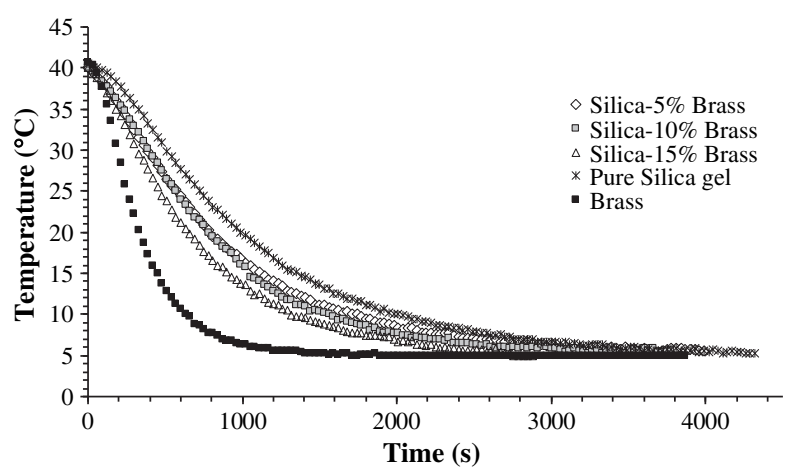

Fig. 7 - Variations of center temperature of Silica gel-Brass adsorbent bed with $0 \%, 10 \%, 15 \%$ and $100 \%$ brass weight.

expectation and the lowest decreasing rate of the center temperature is observed for the stainless steel with 2.8$4.75 \mathrm{~mm}$. The temperature decrease of brass pieces is greater than stainless steel but smaller that $\mathrm{Al}$ and $\mathrm{Cu}$ pieces. The highest decreasing rate is seen for the aluminum pieces with $1.0-2.8 \mathrm{~mm}$. The temperature decrease of aluminum and copper pieces are overlapped for $2.8-4.75 \mathrm{~mm}$ piece size. The temperature decrease of aluminum pieces is steeper than the copper pieces for 1.0-2.8. The wide size of the metal pieces (from 1.0 to $2.8 \mathrm{~mm}$ and from 2.8 to $4.75 \mathrm{~mm}$ ) and some differences between their shapes may be the reason of higher heat transfer rate in the bed containing aluminum pieces. Fig. 4 also indicates the effect of piece size on the heat transfer rate. The decreasing rate of temperature for the bed with $1.0-2.8 \mathrm{~mm}$ stainless steel pieces is slow but not as much as that of the bed with $2.8-4.75 \mathrm{~mm}$. The heat transfer rate through the bed enhances with decreasing size of metal pieces due to increasing contact area between the granules.

Figs. 5-8 illustrate the variation of center temperature of adsorbent bed with time for four different cases in which the metal pieces with size of $1.0-2.8 \mathrm{~mm}$ are mixed with silica gel at different weight ratios as $0 \%, 10 w t \%, 15 w t \%$ and $100 w t \%$. For all cases, the lowest heat transfer rate belongs to the bed with pure silica gel while the beds with $100 \mathrm{wt} \%$ metal pieces have the highest rate of heat transfer through the bed. The increase of percentage of metal pieces improves the heat

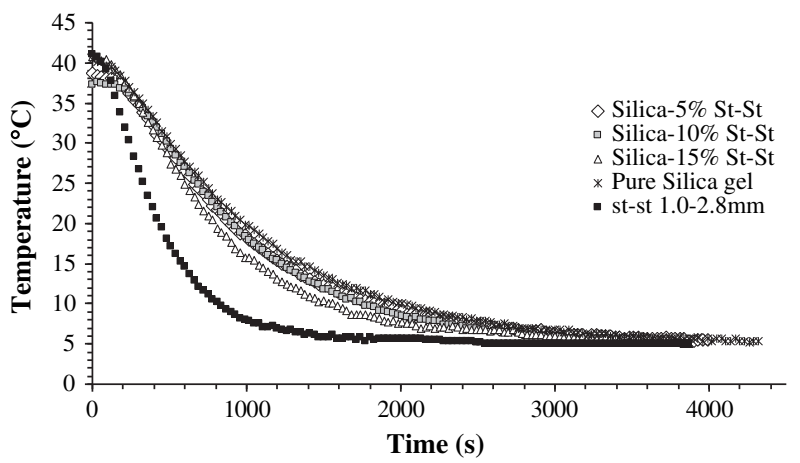

Fig. 8 - Variations of center temperature of Silica gel-St-St adsorbent bed with $0 \%, 10 \%, 15 \%$ and $100 \%$ St-St weight. 
Table 2 - Effective thermal diffusivity and conductivity of adsorbent bed with different mixtures of silica gel-metal and pure silica gel.

\begin{tabular}{|c|c|c|c|c|c|}
\hline Samples & $\begin{array}{c}\text { Volume } \\
\text { fraction (\%) }\end{array}$ & $\begin{array}{l}\text { Effective thermal } \\
\text { diffusivity }\left(\mathrm{m}^{2} \mathrm{~s}^{-1}\right)\end{array}$ & $\begin{array}{c}\text { Effective thermal } \\
\text { conductivity }\left(\mathrm{W} \mathrm{m}^{-1} \mathrm{~K}^{-1}\right)\end{array}$ & $\begin{array}{l}\text { Improvement of } \\
\text { thermal diffusivity (\%) }\end{array}$ & $\begin{array}{l}\text { Improvement of } \\
\text { thermal conductivity (\%) }\end{array}$ \\
\hline Silica gel & & $1.4 \times 10^{-7}$ & 0.106 & & \\
\hline $5 \% \mathrm{Al}-\mathrm{Si}$ & 12.1 & $2.60 \times 10^{-7}$ & 0.218 & 86 & 106 \\
\hline $10 \% A l-S i$ & 23.5 & $3.40 \times 10^{-7}$ & 0.314 & 143 & 196 \\
\hline $15 \% \mathrm{Al}-\mathrm{Si}$ & 34.7 & $3.60 \times 10^{-7}$ & 0.363 & 157 & 242 \\
\hline $5 \% \mathrm{Cu}-\mathrm{Si}$ & 5.2 & $2.10 \times 10^{-7}$ & 0.187 & 50 & 76 \\
\hline $10 \% \mathrm{Cu}-\mathrm{Si}$ & 10.6 & $2.40 \times 10^{-7}$ & 0.246 & 71 & 132 \\
\hline $15 \% \mathrm{Cu}-\mathrm{Si}$ & 15.5 & $2.80 \times 10^{-7}$ & 0.324 & 100 & 206 \\
\hline 5\%Brass-Si & 4.5 & $2.00 \times 10^{-7}$ & 0.176 & 43 & 66 \\
\hline $10 \%$ Brass-Si & 8.9 & $2.10 \times 10^{-7}$ & 0.211 & 50 & 99 \\
\hline $15 \%$ Brass-Si & 12.8 & $2.90 \times 10^{-7}$ & 0.327 & 107 & 208 \\
\hline $5 \%$ St-St-Si & 7.6 & $1.55 \times 10^{-7}$ & 0.141 & 11 & 33 \\
\hline $10 \% S t-S t-S i$ & 14.8 & $1.60 \times 10^{-7}$ & 0.169 & 14 & 59 \\
\hline $15 \%$ St-St-Si & 20.3 & $2.10 \times 10^{-7}$ & 0.254 & 50 & 140 \\
\hline
\end{tabular}

transfer rate through the bed containing silica gel. The variations of the center temperature for $\mathrm{Al}$ mixture with $10 \%$ and $15 \%$ weight percentages are close to each other since the effective thermal conductivity of silica gel-metal piece mixtures exponentially varies with metal weight percentage.

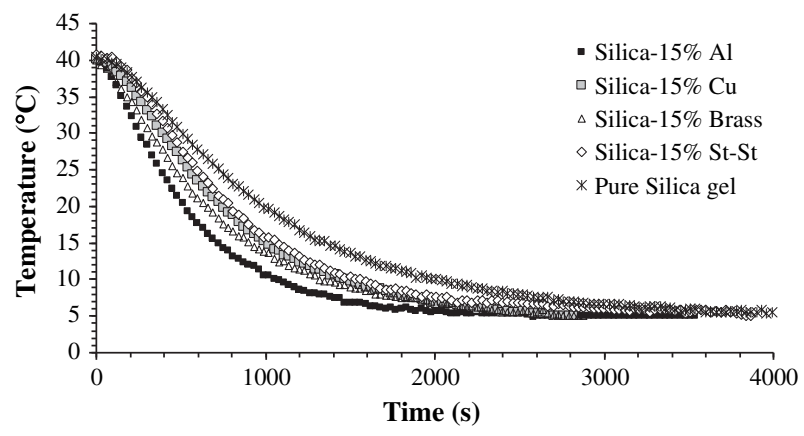

Fig. 9 - Comparison of center temperature profiles of silica gel-metal pieces adsorbent bed for $15 \mathrm{wt} \%$ of aluminum, copper, brass and St-St.

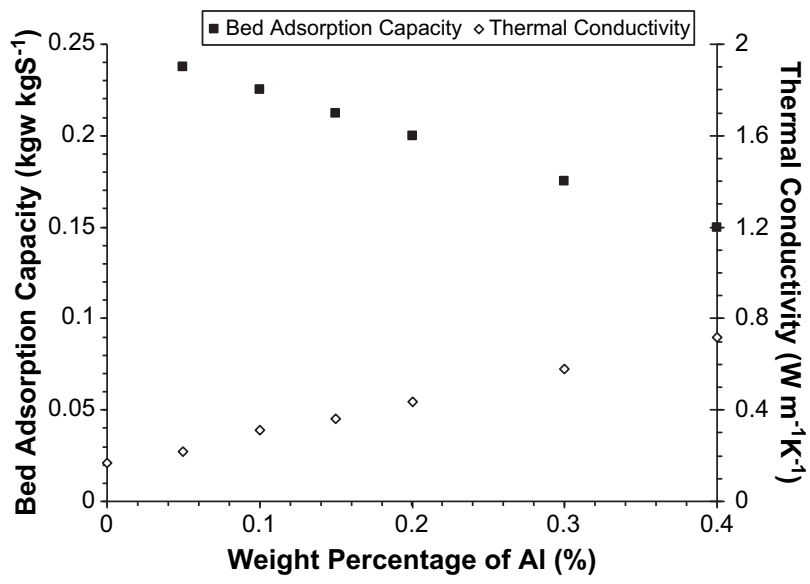

Fig. 10 - The variations of both adsorption capacity and effective thermal conductivity of bed with silica gel-Al mixture against aluminum concentration in the mixture.
In other words, the difference between the effective thermal conductivities of silica gel-metal piece mixtures with different weight percentage becomes larger at higher metal weight percentages. Therefore, the effective thermal conductivities of mixtures with small loadings may be close to each other.

Table 2 illustrates the calculated effective thermal diffusivity and conductivity of the silica gel-metal mixtures with size of $1.0-2.8 \mathrm{~mm}$ whose centerline temperature variations are shown in Figs. 5-8. The improvement of effective thermal diffusivity and conductivity of the silica gel bed by adding metal additives are also calculated and revealed in the same table. The maximum enhancement of the effective thermal diffusivity as $157 \%$ was found for $15 \mathrm{wt} \%$ of $\mathrm{Al}$ additive. For the same weight percentage, copper, brass and St-St additives follow the $\mathrm{Al}$ additive with $100 \%, 107 \%$ and $50 \%$ enhancements, respectively. The minimum improvement of the effective thermal conductivity is observed as $33 \%$ for the mixture with $5 \mathrm{wt} \%$ of St-St and the maximum improvement is observed as $242 \%$ by adding $15 \mathrm{wt} \%$ aluminum.

The comparison of center temperature variation of silica gel-metal mixtures versus time is illustrated in Fig. 9. The mixing ratio is the same for all mixtures as $15 \mathrm{wt} \%$ and the size of metal pieces is $1.0-2.8 \mathrm{~mm}$. The bed with aluminum additive reaches to the equilibrium faster than other mixtures. The interesting point of Fig. 9 is that the silica gel-brass mixture is cooled faster than the silica gel-copper mixture, though the rate of heat transfer in the bed filled with the brass pieces (without silica gel) is smaller than that of the bed with $\mathrm{Cu}$ pieces. The special shape of brass pieces may enhance the cooling rate of the silica gel-brass mixture.

The silica gel-aluminum mixture may be a good choice for the heat transfer enhancement in a granular adsorbent bed since the aluminum additive improves the thermal features of the silica gel bed more than the other metal additives. The increase of percentage of metal pieces improves the heat transfer through the bed. But, it reduces the loading of silica gel granules to the bed as well. The decrease of the adsorbent amount reduces adsorption capacity of the bed. Fig. 10 shows the changes of bed adsorption capacity of the water vapor and the thermal 
conductivity of silica gel-Al mixture versus the aluminum loading. In this figure, the adsorption capacity of silica gel is considered as $25 \%$ which is the maximum adsorption capacity of the used silica gel. The bed adsorption capacity decreases with increasing aluminum amount in the mixture due to the reduction of silica gel amount in the mixture while the effective thermal conductivity of the bed increases with Al loading. The optimum weight percentage for the mixture of aluminum pieces $(1.0-2.8 \mathrm{~mm})$ and silica gel should be determined regarding both thermal conductivity and adsorption capacity of adsorbent bed.

\section{Conclusion}

The results of this study show that the heat transfer rate through a granular adsorbent bed can be increased considerably by addition of metal pieces. The rate of the increase depends on the five parameters as loading amount, thermal diffusivity, thermal conductivity, shape and size of the metal pieces. The decreasing of size of additives increases heat transfer rate through the bed due to the increase of the contact area between the metal piece and silica gel granules, however it may increase the mass transfer resistance. Therefore a special attention should be paid to the selection of shape and size of metal additives.

The heat transfer rate in the bed with $1.0-2.8 \mathrm{~mm}$ size aluminum additive was observed higher than the copper, brass and stainless steel additives. The effective thermal conductivity and diffusivity of the adsorbent bed with pure silica gel were enhanced by $242 \%$ and $157 \%$ with loading $15 \mathrm{wt} \%$ aluminum additive, respectively. The improvement of effective thermal diffusivity and conductivity of an adsorbent bed with Al pieces may reduce the cycle time and increase the SCP. The optimum aluminum weight fraction in a silica gel-Al mixture should be determined by considering the changes of adsorption capacity and thermal conductivity due to mixture addition. Further studies on the effect of shape of metal additives have to be performed.

\section{Acknowledgement}

This work was supported by a grant from State Planning Organization of Turkey.

\section{R E F E R E N C E S}

Aristov, Yu.I., 2009. Optimal adsorbent for adsorptive heat transformers: dynamic considerations. International Journal of Refrigeration 32, 675-686.

Critoph, R.E., Telto, T.Z., Davies, L.N.G., 2000. A prototype of a fast cycle adsorption refrigerator utilizing a novel carbon-aluminium laminate. Proceedings of Institute of Mechanical Engineers 214, 439-448.

Demir, H., Mobedi, M., Ülkü, S., 2008. A review on adsorption heat pump: problems and solutions. Renewable and Sustainable Energy Reviews 12, 2381-2403.

Eltom, M.M.O., Sayigh, M.A.A., 1994. A simple method to enhance thermal conductivity of charcoal using some additives. Renewable Energy 4, 113-118.

Freni, A., Tokarev, M.M., Restuccia, G., Okunev, A.G., Yu.I, Aristov, 2002. Thermal conductivity of selective water sorbents under the working conditions of a sorption chiller. Applied Thermal Engineering 22, 1631-1642.

Gui, Y.B., Wang, R.Z., Wang, W., Wu, J.Y., Xu, Y.X., 2002. Performance modeling and testing on a heat-regenerative adsorptive reversible heat pump. Applied Thermal Engineering 22, 309-320.

Incropera, P.F., DeWitt, P.D., 1996. In: Fundamentals of Heat and Mass Transfer, fourth ed. John Wiley and Sons, New York.

Pino, L., Aristov, Yu., Cacciola, G., Retuccia, G., 1996. Composite materials based on zeolite $4 \mathrm{~A}$ for adsorption heat pump. Adsorption 3, 33-40.

Saha, B.B., Koyama, S., El-Sharkawy, I.I., Kuwahara, K., Kariya, K., Ng, K.C., 2006. Experiments for measuring adsorption characteristics of an activated carbon fiber/ethanol pair using a plate-fin heat exchanger. HVAC\&R Research 12, 767-782.

Ülkü, A.S., Mobedi, M., 1989. Adsorption in energy storage. Proceedings of the NATO Advanced Study Institute on Energy Storage Systems, Series E. Applied Science 167, 487-507.

Wang, S.G., Wang, R.Z., Li, X.R., 2005. Research and development of consolidated adsorbent for adsorption systems. Renewable Energy 30, 1425-1441. 